\title{
How Does the Filter on the Mask Affect Your Breathing?
}

\author{
Dong-Min Kum ${ }^{a}{ }^{(i)}$, Won-Seob Shin ${ }^{a, b}{ }^{(1)}$ \\ aDepartment of Physical Therapy, Graduate School, Daejeon University, Republic of Korea \\ ${ }^{b}$ Department of Physical Therapy, College of Health and Medical Science, Daejeon University, Republic of Korea
}

Objective: The purpose of this study was to determine the effect of the difference in mask filters on the respiration rate of healthy people.

Design: A randomized cross-over design.

Methods: A total of 15 subjects were selected for this study ( $n=15)$. After filling out the Physical Activity Readiness Questionnaire, the selected participants abstained from caffeinated beverages and meals 30 minutes before and sat in a chair 10 minutes before stabilizing their breathing. Afterwards, the lung function test was performed 3 times for each mask, and the maximum value was used. The provided masks were Mask Free, Dental Mask, KF80, and KF94. Exhalation was measured for 6 seconds for each mask, and breathing was stabilized by repeating inhalation and exhalation until the next time.

Results: In this study, the difference in respiratory function according to the mask type was statistically significant except for FEV1 and FVC $(\mathrm{p}<0.05)$. As a result of post-hoc analysis, FVC, FEV1, PEF, and FEF values were significantly lower than those of the control group not wearing a mask $(\mathrm{p}<0.05)$. When wearing KF94, FVC, FEV1, PEF25-25\%, and FEF were significantly lower than when wearing a dental mask $(\mathrm{p}<0.05)$. When wearing a KF80 mask, it was significantly lower in FVC and FEV1 than when wearing a dental mask $(\mathrm{p}<0.05)$. In FEV1/FVC, the difference by mask type was not statistically significant $(\mathrm{p}<0.05)$, but it was lower than the spirometry standard of COPD patients $(\mathrm{FEV} 1 / \mathrm{FVC}<0.7)$.

Conclusions: As Now that wearing a mask is essential, it has been confirmed that the mask affects the respiratory rate.Therefore, in the case of healthy adults, it is recommended to rest after wearing a mask if attention deficit or headache occurs.

People with low breathing capacity are recommended to have low-intensity activities and frequent rest periods after wearing a mask.

Key Words: Mask Filter, respiration, respiratory volume

서론

2019년 중국 우한에서 최초 보고된 코로나 바이러스 (Covid-19)는 2020년 3월 세계 보건 기구가 팬더믹 (Pandemic)을 선언할 정도로 세계적으로 확산되었다[1]. 2021년 1월 28일 질병관리청에서 발표한 자료에 따르면 현재 확인 환자 76,926 명, 사망자 1,386 명으로 집계되고 있으며 현재도 여전히 진행 중이다[2]. Covid-19의 확산 을 막기 위하여 한국 정부는 코로나 행동 수칙을 발표, 집 단 방역(5대 핵심수칙과4개의 보조수칙)을 제시하는 등, 다양한 확산 방지 정책을 제시하고 있다[3]. 이로 인하여 사회 각 분야에 어려움이 발생하고 있는데, 대표적으로
여행, 항공, 체육 분야를 들 수 있다.실내외 체육 시설은 사회적 거리 두기로 인하여 운영이 제한되거나 중단되었 고, 각종 스포츠 경기는 무관중으로 진행되어 참여의 기 회가 제한되고 있는 실정이다[4].

Covid-19의 장기화로 인한 사회적 거리두기 기한이 연 장되면서 신체활동 감소로 인한 우울증 호소들의 정신적 인 문제와 육체적인 문제를 해결하기 위해 보건복지부에 서는 생활 속 사회적 거리두기 세부 지침을 마련하여 실 내 체육시설의 경우 마스크 착용 후 $4 \mathrm{~m}^{2}$ 당 1 명으로 인 원을 제한하여 시행하고 있다[5]. 이런 마스크는 투과율 별로 Dental, KF80, KF94 등으로 국내에서 다양하게 분 류되고 있는데 Dental 마스크는 평균 $1 \mu \mathrm{m}$ 크기의 미세입

Received: Nov 1, 2021 Revised: Nov 23, 2021 Accepted: Dec 8, 2021

Corresponding author: Won-Seob Shin (ORCID https://orcid.org/0000-0002-6515-7020)

Department of Physical Therapy, Applied Science Building, 62, Daehak-ro, Dong-gu, Daejeon, 34520, Republic of Korea

Tel: +82-42-280-2294 Fax: +82-42-280-2295 E-mail: shinws@dju.kr

This is an Open-Access article distributed under the terms of the Creative Commons Attribution Non-Commercial License (http://creativecommons.org/licenses/ by-nc/4.0) which permits unrestricted non-commercial use, distribution, and reproduction in any medium, provided the original work is properly cited.

Copyright @ 2021 Korean Academy of Physical Therapy Rehabilitation Science 
자 $94 \%$ 차단, $\mathrm{KF} 80$ 은 평균 $0.4 \mu \mathrm{m} 0.6 \mu \mathrm{m}$ 크기의 미세 입자 $80 \%$ 이상 차단하며, KF94는 $0.4 \mu \mathrm{m} \sim 0.6 \mu \mathrm{m}$ 크기의 미세입자 $94 \%$ 이상 차단하는 마스크이다[6].

이러한 마스크 사용이 일상 생활이 된 시점에서 최근 국내외에서는 마스크 착용이 인체에 끼치는 영향에 대한 선행 연구들이 발표되고 있다. 해외에서 N95 마스크 위에 Dental 마스크를 착용하여 인체에 어떠한 생리적 변화가 생기는지 확인한 연구에서는 착용자의 활동량이 증가하면 의사소통시 언어 전달성이 낮아짐과 호흡 곤란, 일부 사 람(천식환자, 공황장애, 밀실공포증의 병력이 있는 사람) 에게 부정적인 요인이 발생하였고[7], 마스크 착용 후 운 동시 혈관 확장으로 인한 두통을 보고한 연구와 마스크를 착용한 10 대의 청소년들이 달리기를 하다 사망한 사고가 보고되며[8,9], 장시간의 마스크 착용이 인체에 부정적인 영향을 끼칠 수 있음이 보고되고 있다[10]. 또한 국내의 연구에서 만성 폐쇄성 폐질환환자(Chronic Obstructive Pulmonary Disease; COPD)는 호흡근의 약화로 호흡곤 란과 이동거리, 지구력, 기능적 움직임이 감소하며[34], 폐기능 검사의 결과와 상관관계가 있지 않은 호흡의 문제 는 환자의 일상생활에 영향을 끼친다라고 보고되고 있다 [35]. 하지만 최근 보고되고 있는 논문에서는 어떠한 상황 에서 어떤 마스크를 착용해야 하는지 명시되어 있지 않으 며, 마스크 필터 각각의 효과에 대해서는 발표되고 있으 나, 마스크 필터 별로 호흡에 미치는 영향에 대해 비교, 분석하는 연구는 부족한 실정이다.

이에 본 연구에서는 건강한 10 대에서 40 대의 남자에게 Dental 마스크, KF80, KF94 마스크를 제공하고 마스크 의 필터가 호흡에 어떠한 영향을 끼치는지 알아보고자 한다.

\section{연구 방법}

\section{연구 대상}

본 연구의 대상은 세종시에 거주중인 10 대에서 40 대의 건강한 남자를 대상으로 하고, 선정기준에 적합한 대상자 를 연구에 참여하도록 하였으며, 실험 방법과 목적을 설 명하여 서명을 받아 동의를 얻는 방법으로 진행하였다. 선정 기준은 과거에 심폐질환이 없는 자, 현재에 심폐 질 환이 없는 자, 호흡 평가를 숙지하고 시행할 수 있는 자이 며, 제외 기준은 과거에 심폐 질환이 있었던 자, 현재에 심폐 질환이 있는 자, 호흡 평가를 숙지하지 못하고 시행 할 수 없는 자이다.

대상자는 Cohen의 표본 추출 공식에 따른 표본 수 계 산 프로그램인 G*Power 프로그램(version 3.1.9.2, Dusseldorf, Germany)을 이용하여 산출하였다. 선행 연구의 그룹 간
변수의 평균과 표준 편차를 대입하여 효과 크기를 산출하 였다. 본 연구는 대전대학교 기관생명윤리위원회의 승인 을 받은 후에 연구가 진행되었다(IRB:1040647-202110 -HR-013-01).

\section{연구 절차}

본 연구의 설계는 Randomize Cross-over Design으로 각각의 대상자에 마스크를 필터별로 제공하여 마스크 별 호흡의 차이를 확인하였다.

\section{실험 방법}

\section{폐기능 검사}

대상자는 총 20 명으로 $(\mathrm{n}=20)$ 산출되었고, 5 명이 최종 탈락되어 15 명으로 선정되었다 $(\mathrm{n}=15)$. 선정된 이들은 PAR-Q(신체 활동 준비도 설문지)를 작성후, 30 분전 카페 인 음료와 식사를 금지하고 10 분전 의자에 앉아 호흡을 안정화시켰다. 이 후 마스크 Free, Dental 마스크(3중 필 터 Dental 마스크, WoolryWoolry, China), KF80(크린가 드 황사 마스크 수프림 플러스, 유한 킴벌리, Korea). KF94(피엔티디웰킵스 KF94, 존스미디어, Korea)의 마스 크를 제공하여 마스크를 착용하고 그 위에 실리콘 풀페이 스 마스크를 착용하여 호흡 누출 방지를 위해 헤드 스트 랩으로 고정하고 호흡의 분산을 최대한 막은 상태에서 6 초간 호흡을 내뱉는 것을 측정하고 다음 시기까지 흡기와 호기를 반복하여 호흡을 안정시켰으며[33], 마스크 교체 시 1 분간의 호흡 안정기를 두었다[6,11]. 폐기능 검사는 개인의 호흡능력을 객관적으로 측정하고 폐가 얼마나 잘 환기 되고 가스가 교환하는지 측정하는 검사로 총 3 회씩 실시하였으며, 그중 최대값을 사용하였다 $[12,36]$. 대상자 의 수는 Jung(2002)의 선행연구를 참고하여 15 명이 산출 되었고 탈락률을 고려하여 20명을 모집하였다.

\section{평가방법 및 측정 도구}

\section{스마트 폐홀량 측정기}

본 연구의 호흡 평가는 폐기능검사 지침에 따라 시행하 였고[10], 스마트 폐활량 측정기(SpirobankSmart ${ }^{\mathrm{tm}}, \mathrm{MIR}$, ITA)를 사용하였다(Figure 1). 스마트 폐활량 측정기는 $30 \mathrm{~mm}$ 의 일회용 깔때기를 사용하여 호흡을 하면, 호흡의 지속시간과 호흡의 크기를 측정해 분석해 주는 장비이다 [9]. WinspiroPro(version 8.4, MIR, ITA)소프트웨어를 사용해 호흡 측정에 가이드 라인을 제시해주며 이 장비들 은 $\mathrm{MDD} \mathrm{CE}(9826)$ 인증을 받아 측정에 정확성을 가진 다. 호흡 평가 중 코로 호흡이 분산되는 것을 방지하기 위 


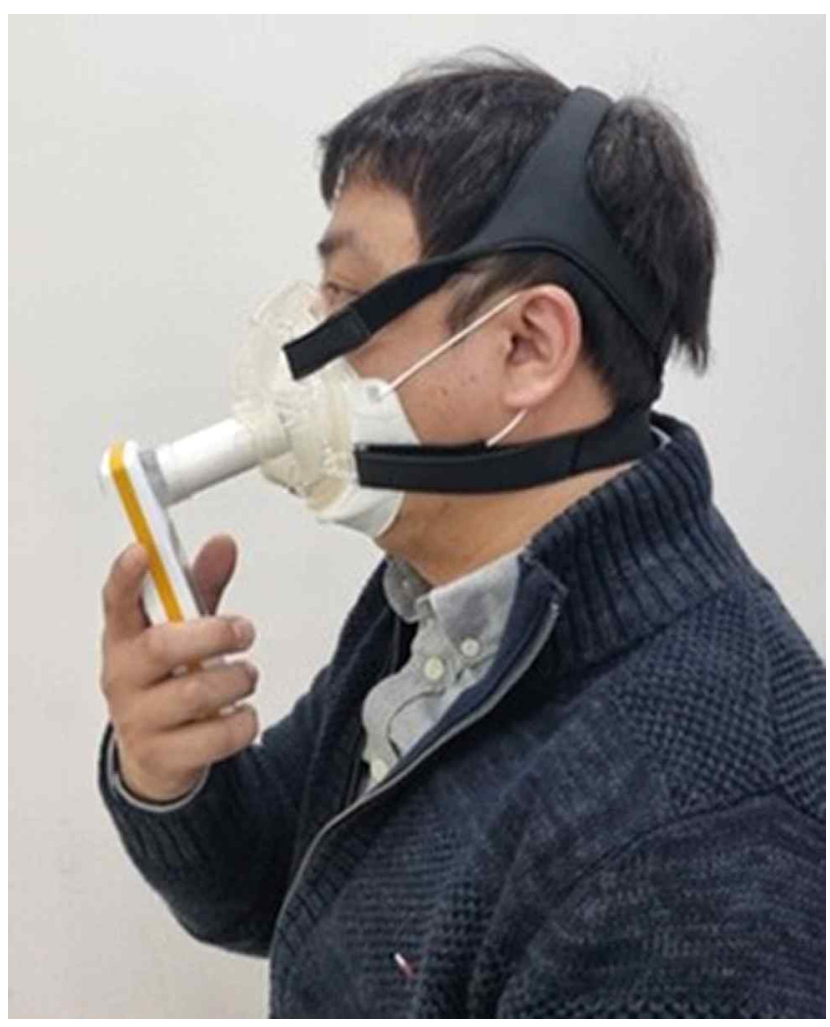

Figure 1. Spirometry with silicone full face mask

해 실리콘 풀 페이스 마스크(Galemed, Taiwan)을 사용하 였다(Figure 1).

\section{측정항목}

측정 항목은 FVC(Forced vital capacity), FEV1(Forced expiratory volume. 1 second), PEF(Peak expiratory flow), FEF 25-25\%(Forced expiratory flow), MVV (Maximal voluntary ventilation), FEV1/FVC(Forced expiratory volume. 1 second/Forced vital capacity)이다 [11]. $\mathrm{FVC}$ 는 최대로 숨을 들이 쉰 다음, 최대 노력으로 끝까지 내쉬었을 때 공기량을 말하며 성인의 경우 남자는 $3 \mathrm{~L}$ 이상, 여자는 $2 \mathrm{~L}$ 이상의 기준을 가진다[12]. FEV1는 첫 1 초간 얼마나 빨리 숨을 내쉴 수 있는지 보는 지표이
다. 성인의 경우 폐활량의 $75 \%$ 이상, 2 초 동안 $85 \%$ 이상, 3 초 동안 $95 \%$ 이상을 배출한다[13]. PEF는 최대 흡기 상태에서 최대의 힘으로 호기할 동안 만들어지는 Maximal Flow를 의미한다[15,16]. FEF $25-25 \%$ 는 총 폐활량에서 처음과 끝 $25 \%$ 씩을 제외한 중간 $50 \%$ 의 평균적인 유량을 평가하는 지표이다. 성인은 $2.7 \sim 4.5 \mathrm{~L} / \mathrm{min}$ 를 가지며 환자 의 노력과 비교적 연관성이 떨어지는 값이다[19]. $\mathrm{MVV}$ 는 최대 환기량으로 자발적 최대 노력으로 1 분간 호흡할 수 있는 환기량이다[6,18]. 기준은 약 $160 ~ 180 \mathrm{~L} / \mathrm{min}$ 이다 [16]. $\mathrm{FEV} 1 / \mathrm{FVC}$ 는 폐에서 강제로 내쉴 수 있는 공기의 양을 측정하는 것으로, 이 비율은 만성폐쇄성 폐질환 (COPD)와 같은 폐쇄성 폐질환의 진단 및 치료에 사용된 다. 기준은 $\mathrm{FEV} 1 / \mathrm{FVC}<0.7$ 이다[11,17].

\section{자료 분석}

본 연구는 자료분석은 SPSS(21.0 Version, IBM Inc., USA) 통계프로그램을 사용하여 분석하였고, 피험자 15 명 이 각 마스크 별 4 개의 조건에 참여하여 얻은 총 60 회의 호흡 능력 차이에 관한 실험결과에 대해 평균과 표준편차 를 제시하였다. 마스크착용과 종류에 따른 통계적 차이는 반복 측정 분산분석(Repeated Measures ANOVA)로 검 증하였고, 사후 분석은 Bonferroni correction으로 진행하 였다 통계적 유의수준은 $\alpha=0.05$ 로 정하였다.

\section{연구 결과}

연구 대상자 20 명중 5 명은 실험에 참여하지 않아 탈락 되어 총 15 명으로 실험이 진행되었다. 15 명의 평균 연령 은 29.47세로 나타났으며 평균 신장 $176.33 \mathrm{~cm}$, 평균 체 중은 $73.33 \mathrm{Kg}$ 이다(Table 1$)$.

본 연구에서 마스크의 종류에 따른 호흡기능의 차이는 $\mathrm{FEV} 1$ 과 $\mathrm{FVC}$ 를 제외하고 모두 통계적으로 유의하게 나 타났다 $(\mathrm{p}<0.05)$. 사후 분석결과, 마스크를 착용하지 않은 대조군에 비해 $\mathrm{FVC}, \mathrm{FEV} 1, \mathrm{PEF}, \mathrm{FEF}$ 값이 유의하게 낮게 나타났다 $(\mathrm{p}<0.05)$. KF94를 착용하였을 때는 Dental 마 스크를 착용하였을 때에 비해 FVC, FEV1, PEF25-25\%, $\mathrm{FEF}$ 에서 유의하게 낮게 나타났다 $(\mathrm{p}<0.05) . \mathrm{KF} 80$ 마스크

Table 1. General characteristics

\begin{tabular}{llll}
\hline Variables & Male $(\mathbf{n}=\mathbf{1 3})$ & Female $(\mathbf{n}=\mathbf{2})$ & Total $(\mathbf{N}=\mathbf{1 5})$ \\
\hline Age $($ year $)$ & $30.62(9.11)$ & $22.00(1.41)$ & $29.47(8.97)$ \\
Height $(\mathrm{cm})$ & $176.31(6.45)$ & $176.50(16.26)$ & $176.33(7.38)$ \\
Weight $(\mathrm{kg})$ & $73.92(12.54)$ & $77.00(29.70)$ & $74.33(14.11)$ \\
\hline
\end{tabular}

The values are presented as mean (SD) 
Table 2. Differences in respiratory according to mask types

\begin{tabular}{llllll}
\hline Variables & KF94 & KF80 & Dental & Control & F(p) \\
\hline FVC $(\ell)$ & $2.84(0.22)^{\dagger^{\dagger}}$ & $3.05(0.23)^{\dagger^{\dagger}}$ & $3.62(0.20)^{\dagger}$ & $5.47(0.31)$ & $22.982(.000)^{*}$ \\
FEV1 $(\ell / \mathrm{sec})$ & $1.81(0.22)^{\dagger^{\dagger}}$ & $2.04(0.22)^{\dagger^{\dagger}}$ & $2.56(0.20)^{\dagger}$ & $3.90(0.22)$ & $60.145(.000)^{*}$ \\
PEF $(\ell / \mathrm{sec})$ & $2.86(0.39)^{\dagger^{\dagger}}$ & $3.31(0.48)^{\dagger}$ & $3.99(0.37)^{\dagger}$ & $7.37(0.75)$ & $16.464(.000)^{*}$ \\
FEF 25-25\% $(\ell / \mathrm{sec})$ & $1.52(0.23)^{\dagger^{\dagger}}$ & $1.91(0.27)^{\dagger}$ & $2.28(0.35)^{\dagger}$ & $3.53(0.26)$ & $34.301(.000)^{*}$ \\
MVV $(\ell / \mathrm{min})$ & $63.28(7.59)^{\dagger^{\dagger}}$ & $73.76(8.06)^{\dagger}$ & $87.22(7.06)^{\dagger}$ & $136.62(7.78)$ & $52.988(.000)^{*}$ \\
FEV1/FVC & $.620(.05)$ & $.65(0.04)$ & $.71(0.05)$ & $.72(0.03)$ & $2.846(.063)$ \\
\hline
\end{tabular}

The values are presented as mean (SD).

${ }^{*} \mathrm{p}<0.05 .{ }^{\dagger}$ significant difference compared to control, ${ }^{ \pm}$significant difference compared to Dental.

FVC : Forced Vital Capacity, FEV1 : Forced Expiratory Volume. 1 second, PEF : Peak Expiratory Flow, FEF 25-75\% : Forced Expiratory Flow 25-25\%, MVV : Maximal Voluntary Ventilation.

를 착용하였을 때는 Dental 마스크를 착용하였을 때에 비 해 FVC, FEV1에서만 유의하게 낮게 나타났다 $(\mathrm{p}<0.05)$. $\mathrm{FEV} 1 / \mathrm{FVC}$ 는 마스크의 종류별 차이가 통계적으로 유의 하지 않았다 $(\mathrm{p}<0.05)($ Table 2$)$.

\section{논의}

Covid-19는 SARS-CoV-2에의 한 감염질환으로 호흡 기 질환을 유발하며 심한 경우 폐렴을 일으킨다[24]. 따라 서 정부는 마스크 사용 권고 사항을 2002년 3월에 개정 된 사항으로 발표하였고, $\mathrm{KF94,} \mathrm{KF80의} \mathrm{마스크} \mathrm{착용을}$ 권장하고 있다[25]. 이는 Covid-19의 감염을 $10.52 \%$ 감 소시킬 수 있기 때문이다[11]. 하지만 장시간의 마스크 착 용은 마스크 내부의 호흡에 영향을 끼쳐 사용 가능한 산 소가 줄어들고 호흡에 방해를 끼칠 수 있다[27]. 또한 고 탄소 저산소증은 심장의 과부화 및 혐기성 대사, 신장 과 부화를 증가시킬 수 있으며, 만성질환의 근본적인 병리를 악화시킬 수 있다[8]. 선행 연구에서 마스크를 착용 후 이 산화탄소의 농도가 높아지는 것을 확인하였고 이는 마스 크가 이산화탄소를 외부로 배출하는 것에 대해 방해가 됨 을 알 수 있다[7]. 마스크로 제한된 공간에서 호흡하면 동 맥의 이산화탄소의 농도가 증가한다[28]. 이는 COPD와 유사한 불편함, 피로, 현기증, 두통, 숨가쁨, 근육약화, 졸 음과 같은 생리적 효과를 보일 수 있다. 이런 현상은 마스 크필터의 등급이 높을수록 더 강한 효과가 나타난다고 할 수 있다[8]. 이는 마스크의 착용이 Covid-19의 감염확률 을 줄일 수 있으나 신체에 가해지는 문제에 관한 최적의 마스크의 활용법에 대한 연구가 필요하다는 의미이다.

본 연구는 안정된 상태에서 호흡의 상태를 마스크 필터 별로 구분하여 필터가 호흡에 미치는 영향에 대해 알아보 고자 하였다. 이 실험의 결과로 마스크의 착용은 일반적
인 호흡에 비해 어떠한 마스크를 착용하여도 호흡에 영향 을 끼침이 확인되었다. 안정된 상태에서 측정되었음에도 마스크 착용 후 호흡이 통계적으로 유의하게 감소되었고 이는 호흡능력에 유의미한 차이가 발생하였다.

마스크별 비교에서는 Dental 마스크를 착용 후 호흡평 가를 한 것과 KF94를 착용하고 진행한 호흡평가가 더 낮 은 호흡능력을 보여주었다. Dental 마스크 착용 후 호흡 평가에서 $\mathrm{FVC}$ 는 평균 $3.62 \mathrm{~L}$ 로 $\mathrm{FVC}$ 성인의 기준인 $3 \mathrm{~L}$ 를 초과하였고 $\mathrm{FEV} 1$ 은 일반 호흡의 $76 \%$ 로 정상범위에 들어와 호흡능력에 유의미한 차이는 보이지만 정상 호흡 범위안에 들어와 있다 할 수 있다. 그러나 KF94는 FVC 값이 성인인의 기준 $3 \mathrm{~L}$ 보다 적은 $2.84 \mathrm{~L}$ 로 정상범위 보다 낮은 호흡 능력을 보여주었고 FEV1의 값도 일반 호흡의 $54 \%$ 로 정상 범위보다 낮은 능력을 보여주었다.

이러한 $\mathrm{KF} 94$ 의 값은 $\mathrm{COPD}$ 가 있는 환자보다 낮은 $\mathrm{FEV} 1 / \mathrm{FVC}$ 값을 나타냈는데 성인의 폐활량 측정법에서 기관지확장제 사용 전 $\mathrm{FEV} 1 / \mathrm{FVC}<0.7$ 으로 $\mathrm{KF} 94$ 는 0.62 으로 $\mathrm{COPD}$ 환자의 폐활량보다 낮은 값을 보이고 있 다[12]. 하지만 바이러스의 좋은 여과 효율을 생각하면 KF94를 사용하는 것이 바람직하다. Dental 마스크는 어 느 정도 효과가 있었으나 KF94만큼은 아닌 것으로 확인 되었다[9].

Covid-19의 유행이 시작된 후 마스크는 일상생활 만 아니라 운동 및 각종 여과생활에서도 필수적으로 착용되 고 있다. 바이러스를 차단하기위해 높은 등급의 마스크를 착용한다면 휴식의 빈도를 높이고 운동강도를 조절하는 등의 주의가 필요하다[24]

본 연구에서는 일반적인 호흡과 마스크 필터 별 호흡 능력에 차이에 대해서 알아보았다. 마스크 필터의 차이와 상관없이 마스크를 착용한 호흡과 일반적인 호흡은 차이 가 있었으며, Dental 마스크와 KF등급의 마스크의 호흡 
차이는 유의하게 나타났다. 바이러스의 전파방지를 위해 서는 $\mathrm{KF}$ 등급의 마스크가 당연하나 그에 따른 호흡량의 변화를 확인하였다. 이에 건강한 성인의 경우 마스크 착 용 후 주의력 결핍이나 두통 발생시 휴식을 권장하며, 호 흡능력이 떨어지는 $\mathrm{COPD}$ 환자나 낮은 호흡능력을 가진 사람들은 마스크 착용 후 활동시에는 낮은 강도의 활동과, 잦은 휴식시간을 가질 것을 권장한다. 이 연구는 안정된 상태에서 호흡능력의 차이를 비교하여 운동 강도에 따른 필터 별 호흡능력에 차이에 대해서는 알아보지 못하였고 추후 연구에서는 마스크 필터에 따른 운동 강도 별 호흡 능력의 차이에 대하여 알아보아야 할 것이다.

\section{이해 충돌}

본 연구의 저자들은 연구, 저작권 및 출판과 관련하여 잠재적인 이해충돌이 없음을 선언합니다.

\section{참고문헌}

1. Rothan HA, Byrareddy SN. The epidemiology and pathogenesis of coronavirus disease (COVID-19) outbreak. Journal of autoimmunity 2020;109:102433.

2. Sim MY, Psychological Effects of the coronavirus disease 2019 pandemic Korean Journal of Medicine 2020;95(6):360-3.

3. Noh YH, Shin YG. A Study on the Library Activation Plan Using Autonomous Objects. J. Korean Library and Information Science Society 2021;52(1):27-54.

4. Kwon OJ. A Case Study of Changes in the Exercise Behavior of the Elderly by COVID-19. Korean J. Sport Psychol 2020;31:123-34.

5. Yu SS, Oh HJ. Using Online Records for Construction of White Papers on Disaster Management. J. Korean Society of Archives and Records Management 2021;21(2):135-54.

6. Jung JY, Kang C, Seong Y, Jang SH, Lee JY. Effects of Wearing COVID-19 Protective Face Masks on Respiratory, Cardiovascular Responses and Wear Comfort During Rest and Exercise. Fashion $\&$ textile research Journal 2020;22(6);862-72

7. Roberge, Raymond J.; ROBERGE, Marc R. Cloth face coverings for use as facemasks during the coronavirus (SARS-Cov-2) pandemic: what science and experience have taught us. Disaster Medicine and Public Health Preparedness 2020;1-29.
8. Chandrasekaran, Baskaran; FERNANDES, Shifra. "Exercise with facemask; Are we handling a devil's sword?"-A physiological hypothesis. Medical hypotheses 2020;144,110002.

9. Rosner, E. Adverse effects of prolonged mask use among healthcare professionals during COVID-19. J. Infect Dis Epidemiol 2020;6(3):130.

10. Haischer, Michael $H$. Who is wearing a mask? Gender-, age-, and location-related differences during the COVID-19 pandemic. Plos one 2020;15(10), $\mathrm{e} 0240785$.

11. Dean E, Frownfelter, Donna. Cardiovascular and pulmonary physical therapy-E-Book, Evidence and practice 2014.

12. Sutbeyaz, Serap Tomruk. Respiratory muscle training improves cardiopulmonary function and exercise tolerance in subjects with subacute stroke: a randomized controlled trial. Clinical rehabilitation 2010;24(3):240-50.

13. Kim YS. Lung function test training course organized by the Korean Tuberculosis and Respiratory Association: Primary theoretical education: Quality control guidelines for lung function tests. Korean Tuberculosis and Respiratory Association Fall Conference 2013;116(0):57-65.

14. Lin, Ching-Hsiung. Novel App-Based Portable Spirometer for the Early Detection of COPD. Diagnostics 2021;11(5):785.

15. Kim, HS, Cho SH. Correlation between Body Composition and Lung Function in Healthy Adults. J. The Korean Society of Integrative Medicine 2020;8(2): 53-61.

16. Lee KC, Choo YK. Inspiratory Muscle Strengthening Training Method to Improve Respiratory Function: Comparison of the Effects of Diaphragmatic Breathing with Upper Arm Exercise and Power-Breathe Breathing. J. The Korean Society of Integrative Medicine 2021;9(3):203-11.

17. Lee YS.Compare the Effects of Inspiratory and Expiratory Muscle Strengthening Training of Normal Adult Respiratory Function. J. Korean Soc Integr Med 2016;4(1):41-7.

18. Kim MCl. The Normal Predicted Value of Peak Expiratory Flow(PEF) Measured by the Peak Flow Meter and Correlation Between PEF and Other Ventilatory Parameters Tuberc Respir Dis (Seoul) 
1998;45(5):1000-11.

19. Hanayama Kozo, Ishikawa Yuka; BACH, John R. AMYOTROPHIC LATERAL SCLEROSIS: Successful Treatment of Mucous Plugging by Mechanical Insufflation-Exsufflation1. American J. physical medicine \& rehabilitation 1997;76(4):338-9.

20. Dechman Gail,Wilson, Christine R. Evidence underlying breathing retraining in people with stable chronic obstructive pulmonary disease. Physical therapy 2004;84(12):1189-97.

21. Seo KC. The effects of pulmonary function in the stroke patients after thoracic expension exercise. J. the Korean Society of Physical Medicine 2012; 7(2):157-64.

22. Yoon SY, Jeong HY, Jeong SM, Kim SY, Kim YK. A Study of Pulmonary Function in Normal Young Persons. Tuvercuiosis and Respiratory Diseases 1983;30(4):184-7.

23. Lim SY, Yoon HI. Interpretation of Pulmonary Function Tests and Optimization of Inhalation Therapy. Korean J. Medicine 2021;96(3):209-217.

24. Lee KH. Diagnosis of chronic obstructive pulmonary disease. Korean J. Med 2009;77(4):401-6.

25. Jin, K. N., Yoon, S. H., Park, C. H., Beck, K. S., Do, K. H., \& Yong, H. S. KSR/KSTR guidelines for the use of diagnostic imaging for COVID-19. J. Korean Soc Radiol 2020;81(3):577-82.

26. Shin NY, Lee KM, Kang YH. A Survey Study of Compliance with Mask-Wearing to Prevent Coronavirus Infections among Korean Adults. J. Korean Acad Fundam Nurs 2021;28(3).

27. Nguyen, My. Mask Mandates and COVID-19 Related Symptoms in the US. ClinicoEconomics and Outcomes Research: CEOR 2021;13:757.

28. Kwon JH. A study of disposable micro dust-mask design for bicycle users. J. Digital Convergence 2018;16(12):571-7.

29. Yu JW, Kim UJ, Hur NK. A Numerical Analysis on Respiratory Flow Characteristics in Wearing a Mask. In: Korean Society of Mechanical Engineers Spring and Autumn Conference. The Korean Society of Mechanical Engineers 2018;426-7.

30. Jung JY. Korean COPD Guideline. Obstructive Lung Disease 2021;9(1):21-24.

31. Yoon CS, Go SB, Park JH. Comparisons of Certification Standards for Mask and Review on
Filtration Efficiency for Viruses. Korean Industrial Hygiene Association Journal 2020;30(2):109-23.

32. Sakaguchi H, Wada K, Kajioka J, Watanabe M, Nakano R, Hirose T, Maintenance of influenza virus infectivity on the surfaces of personal protective equipment and clothing used in healthcare settings. Environmental health and preventive medicine 2010;15(6):344-9.

33. Flkenzer S, Uhe T, Lavall D, Rudolph U, Falz R, Busse M, Laufu U,Effects of surgical and FFP2/N95 face masks on cardiopulmonary execise capacity. Clinical Research in cardiology 2020; 109(12):1522-30.

34. Lee SC, You SK, Yang SB, Park DS, Reliability and validity of an electronic inspiratory loading device for assessing pulmonary function in patients with COPD. Physical therapy rehabilitation science 2021;10:16-21.

35. Kim SH, Jeong JH, Lee BJ, Shin MJ, Shin YB, Effects od and barrier to hospital-based pulmonary rehabilitation in patients with chronic obstructive pulmonary disease. Physical therapy rehabilitation science 2020;9:82-9

36. Kim BS, Lee MM, A study on the clinical usefulness, validity, and test-retest reliability of the spiokit, a device that combines the pulmonary function test and respiratory muscle strength test. Physical therapy rehabilitation science 2020;9:120-30 